\title{
The Availability, Pricing and Affordability of Three Essential Asthma Medicines in 52 Low- and Middle-Income Countries
}

\author{
Zaheer-Ud-Din Babar • Charon Lessing • \\ Cécile Mace $\cdot$ Karen Bissell
}

Published online: 15 October 2013

(C) Springer International Publishing Switzerland 2013

\begin{abstract}
Background Almost 300 million people suffer from asthma, yet many in low- and middle-income countries have difficulty accessing essential asthma medicines. Availability, price and affordability of medicines are likely to affect access. Very few studies have included asthma medicines, particularly inhaled corticosteroids, in these countries. Reflections about international reference prices (IRPs) are generally absent from pricing studies, yet some IRPs may be masking the extent of access problems.

Objectives Our objective was to determine the availability, pricing and affordability of beclometasone, budesonide and salbutamol, the three asthma medicines on the World Health Organization's Model List of Essential Medicines (EML) in selected low- and middle-income countries and to reflect on the appropriateness of using IRPs.

Methods A cross-sectional pricing survey was conducted in 52 countries. Data were collected on country demographics including national currency, \$US exchange rate and daily wage of the lowest-paid unskilled government worker. Pricing and availability data were collected for salbutamol, beclometasone and budesonide in two private retail pharmacies, the national procurement centre and a main public hospital.
\end{abstract}

Zaheer-Ud-Din Babar $(\bowtie) \cdot$ C. Lessing

School of Pharmacy, The University of Auckland, Private Mail

Bag 92019, Auckland, New Zealand

e-mail: z.babar@auckland.ac.nz

C. Mace $\cdot$ K. Bissell

International Union Against Tuberculosis and Lung Disease, Paris, France

K. Bissell

School of Population Health, The University of Auckland,

Auckland, New Zealand
Results Availability was particularly poor for corticosteroids, and worse in national procurement centres and main hospitals. The surveyed strength of beclometasone was only on the EML of ten countries. Considerable variability was found in pricing and affordability across countries. Procurement systems appeared largely inefficient when Asthma Drug Facility prices were applied as references. Some countries appear to be subsidising asthma medicines, making them free or less expensive for patients, while other countries are applying very high margins, which can significantly increase the price for patients unless a reimbursement system exists. Conclusions Findings raise important policy concerns. Availability of inhaled corticosteroids is poor; many EMLs are not updated; IRPs can be misleading; health systems and patients are paying more than necessary for asthma medicines, which are unaffordable for many patients in many countries.

\section{Key Points for Decision Makers}

- The availability of inhaled corticosteroids was particularly low, and many national Essential Medicines Lists appear not to have been updated to incorporate inhaled corticosteroids.

- Considerable variation was found in the pricing structures across the countries, and most procurement systems appeared to be inefficient when Asthma Drug Facility (ADF) prices were used as comparison. Many health systems, as well as patients, appear to be paying more than necessary for asthma medicines, and many prices are unaffordable for patients.

- There was also significant variation in the affordability of these three medicines across countries; some providing subsidies while others appeared to apply high prices for patients. 


\section{Introduction}

This study set out to explore the availability, pricing and affordability in low- and middle-income countries of the three medicines on the World Health Organization's (WHO) Model List of Essential Medicines (EML) [1] for the management of asthma (beclometasone, budesonide and salbutamol). The study also reflects the use of international reference prices (IRPs) in conducting such studies.

Internationally, the cost of medicines constitutes a sizeable amount of healthcare budgets [2]. In many countries, both pricing and availability are likely to be key factors that influence access to medicines across a range of medical conditions. High-income countries within the Organisation for Economic Co-operation and Development (OECD) spend on average $18 \%$ of their health budget on medicines, while some low- and middle-income countries spend up to $80 \%$ [3]. In these countries, medicines are often unaffordable for large parts of the population when people are required to purchase medicines as an out-ofpocket expense. Unfortunately, this is often at the expense of food and other more basic living requirements [4-6].

The provision of affordable essential medicines within developing countries is one of the Millennium Development Goals (MDG) and is called MDG Target 8E [7, 8]. High prices are known to be a major barrier to access to essential medicines in developing countries [9]. However, studies and routinely collected data on medicine prices are still scarce. Measuring, understanding and monitoring medicine prices are fundamental activities if countries are to develop pricing policies that will improve both the availability and the affordability of medicines [2, 10, 11]. Without such data and the incentive and pressure to act upon them, national policies are likely to make little progress towards achieving the MDG target for essential medicines.

Approximately 300 million people worldwide are affected by asthma [12]. Although asthma cannot be cured, it can be managed effectively if patients have access to regular medicine [13-17]. Global concern about high levels of unnecessary morbidity and mortality associated with this condition, as well as the economic impact on health systems when asthma goes untreated, indicates the importance of exploring medicine pricing and ensuring availability of essential asthma medicines in developing countries [18-20].

According to WHO, although effective treatments exist for managing asthma, access to the relevant medicines is believed to be sub-optimal in many low- and middleincome countries [9]. Beclometasone and salbutamol are the standard medicines for asthma management, but there are reports about some low-income countries having problems making a continuous supply of these affordable medicines available [4, 9, 21, 22]. A study evaluating availability, pricing and affordability of essential asthma medicines in five Indian states concluded that the lowest paid unskilled government worker requires 2 days' wages (approximately \$US7) to purchase one inhaler each of beclometasone and salbutamol [22].

Although some work on access to essential asthma medicines has been undertaken, the true extent of the problem has not been adequately quantified [9], and the policy implications are unlikely to have been adequately addressed in all countries $[9,18,22,23]$. Thus, the aim of this cross-sectional 'snapshot' study was to determine the availability, pricing and affordability of three essential asthma medicines in 52 low- and middle-income countries and to reflect on the appropriateness of using IRPs in such studies.

\section{Methods}

\subsection{Sampling Strategies and Stakeholder Engagement}

Low- and middle-income countries were the target countries for this study. The definitions for low- and middleincome countries were taken from the World Bank income groups [24] and convenience sampling was used to select countries [25]. Letters of invitation to participate were sent to a select group of individuals (e.g. clinicians, pharmacists, nurses, programme managers, academics) known to the authors and/or the International Union Against Tuberculosis and Lung Disease (The Union) who work in lung health and/or public health research in 70 low- and middle-income countries. The invitation letter and data collection form were developed by the authors, and the distribution process was handled by The Union's Asia Pacific regional office in Singapore. The letter of introduction outlined the study, participants' responsibilities and instructions for participation. The data collection form was included with the letter. Non-responders were followed up by email or telephone.

This study was approved by the University of Auckland Human Participants Ethics Committee (Reference number: 2011/193). The participants provided their verbal consent to participate in the study. The 'Participant Information Sheet' indicated that, by participating in the study and providing the information requested on the data collection sheet, consent is deemed to have been given. The Ethics Committee approved this procedure.

\subsection{Sourcing Reference Pricing Data}

IRP and Asthma Drug Facility (ADF) prices were used as benchmarks to compare whether the prices were low or high [26]. IRPs are the median of procurement or tender 
prices listed in the Management Sciences for Health (MSH) 2010 price indicator guide for multi-source products [26]. Multisource pharmaceutical products may or may not be therapeutically equivalent. However, those products that are therapeutically equivalent are interchangeable. The IRPs are mostly from not-for-profit suppliers. The prices generally do not include insurance or transportation charges [26]. A ratio can be calculated by comparing the IRP with the local price. This ratio is an expression of how much greater or less the median local medicine price is relative to the IRP, e.g. a price ratio of 2 would mean that the local medicine price is twice the IRP. If a ratio of 1 or $<1$ is reported, prices are deemed reasonable in the public sector. For the private sector, a ratio of $<3$ is considered to indicate reasonable pricing [26, 27].

The IRP (the $2010 \mathrm{MSH}$-derived median supplier price) for salbutamol was based on data from eight different sources. Price information used to compile reference prices for beclometasone and budesonide was much more limited. Two wide-ranging prices (\$US2.38 and \$US13.72) form the basis of the MSH beclometasone IRP, and only one data source was used to generate the budesonide IRP [26]. For this reason, we chose to use the prices obtained by The Union's ADF as additional reference pricing [23]. Through the ADF, many low- and middle-income countries can now purchase the quality-assured, affordable asthma medicines they need. The ADF organised international restricted competitive tenders among qualified products from selected manufacturers to obtain the best prices for qualityassured products [23].

\subsection{Development of Data Collection Forms}

Standardised data collection forms were developed and pilot-tested in four countries (Bangladesh, Egypt, Sudan and Zimbabwe). The problems with the pre-pilot form were graded as low, moderate and high. Broadly, they included the need to add variables, to determine why fields were not being completed consistently and to improve instructions and layout. The final data collection forms were made available in English, French and Spanish. The form had three sections: (i) three pages of detailed instructions, (ii) a demographic section (contact details, profession of the data collector, national currency, exchange rate in \$US and daily wage of lowest paid unskilled government worker), (iii) the data collection sheets on medicine availability and prices in the different facilities: two private retail pharmacies (patient price), the national procurement centre (catalogue price), one main public hospital (patient price). A participant information sheet was made available for the data collectors and for managers of facilities that were considering participating. The data collection form is available from the authors upon request.

\subsection{Data Collection}

Availability and pricing data for both the innovator brand (IB) as the reference product and the lowest-priced generic product were sought from each country. Qvar ${ }^{\circledR}$, produced by $3 \mathrm{M}$ Pharmaceuticals, was the reference product for beclometasone; Pulmicort $^{\circledR}$, produced by Astra Zeneca, was the reference for budesonide. For salbutamol, data were collected for three IBs $\left(\right.$ Ventolin ${ }^{\circledR}$, Aerolin ${ }^{\circledR}$ or Salbutan ${ }^{\circledR}$ ), all of which are produced by GlaxoSmithKline. Though Qvar $^{\circledR}$ is a reference product, however to avoid confusion; throughout the article we will be calling it Innovator Brand.

Data were collected by making one visit to two private retail pharmacies, the national procurement centre and a public hospital in the capital or main provincial city of each country (Fig. 1). Data collection occurred between May and July 2011. This enabled calculations of comparative price and affordability across the countries. A search was also conducted by the researchers to locate the latest available national EML for the countries involved and to check whether the survey medicines were included in these lists.

Data were screened for completeness and accuracy. Currency exchange figures were double-checked. Data were entered into a Microsoft ${ }^{\circledR}$ Excel spreadsheet, then cleaned and verified. When data issues were identified, these were considered. If the issue could not be solved appropriately, the country was excluded from the analysis. Adequate datasets were received from 52 countries.

\subsection{Data Management and Analysis}

\subsubsection{Availability}

For each country, the availability of the reference product and the generic, at the specified strengths, was reported for each of the three types of health facility as being (i) not available on survey date; (ii) available on survey date; or (iii) no data. Regarding presence on the national EML, each medicine was listed as being (i) not in national EML; (ii) listed in national EML; or (iii) no data.

\subsubsection{Price Ratios}

Although data were collected from two private retail pharmacies and both prices are listed in the tables, throughout this article we have used the lower price for the comparisons. Price ratios for each medicine available in each country were calculated using MSH 2010 IRPs. The method of comparing local prices with MSH IRPs has been used in WHO and Health Action International (HAI) surveys [28, 29]. Our study calculated a second set of price ratios, using the ADF 2011 procurement prices. Thus, we were able, in turn, to compare the MSH-generated IRP 
price ratios with the ADF-generated price ratios for each medicine.

Some recent studies have used a median price ratio (MPR) of one or less for the public sector and three or less for the private sector as an indicator of efficient procurement $[27,28]$. The WHO and the HAI propose that procurement prices for the lowest-priced available generic should be approximately equivalent to the MSH international supplier/buyer prices (i.e. with a ratio of 1.00 or less). Thus, MPRs of 1.00 or less are interpreted as indicating that the procurement system is working very efficiently, while MPRs above 1.00 suggest they are not working efficiently. It is expected that the MPRs for IB products may be much higher, since the MSH IRPs are for multi-source products. However, price ratios much greater than 2.00 for the lowest-priced generics are considered to be a cause for concern, since this is twice the price of these medicines if procured from international suppliers. [27]

\subsubsection{Affordability and Cost of Annual Treatment}

Affordability of these medicines was computed using the daily wage of the lowest-paid unskilled government worker for each country. The total combined cost of 1 year of treatment with a corticosteroid preventer (beclometasone or budesonide) and a bronchodilator (salbutamol) was calculated. Given that a patient with severe asthma will require approximately 16 corticosteroid inhalers per year and eight salbutamol inhalers per year [30,31], all prices per inhaler were multiplied accordingly to estimate the cost of a year's supply.

It is important to note that some countries may make medicines freely available in the public sector or have social insurance systems in place in the private sector. Since this study did not analyse each country's financing arrangements for these asthma medicines or for their populations, the affordability results may not be totally reflective of the situation for consumers.

\section{Results}

\subsection{Country Demographics}

A total of 70 countries were invited to participate, and collection forms were received from 54 countries, producing an overall response rate of $77.0 \%$. Two countries were excluded from the analysis due to inadequate data provision. Figure 1 shows the cities in which data were collected.

Categorisation of the participating countries by income level is outlined in Table 1 . Of the 52 participating

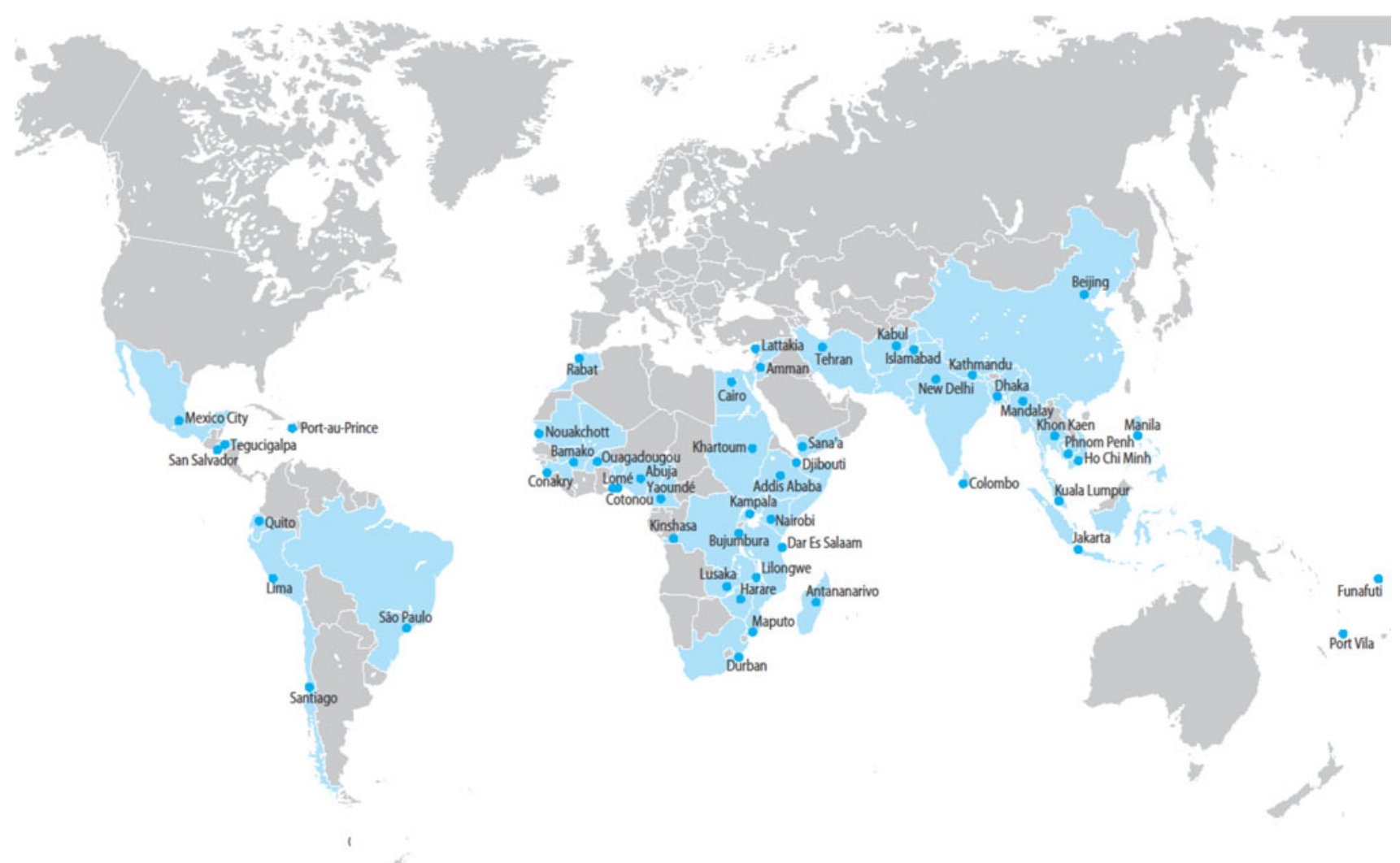

Fig. 1 World map showing the cities in which data were collected for the essential asthma medicines survey 2011 
Table 1 Categorisation of participating countries by World Bank income grouping

\begin{tabular}{|c|c|c|c|}
\hline Country & $\begin{array}{l}\text { World Bank } \\
\text { income group } \\
(2010)\end{array}$ & $\begin{array}{l}\text { Health } \\
\text { expenditure per } \\
\text { capita }^{\text {a }} \text { (\$US) }\end{array}$ & $\begin{array}{l}\text { Expenditure on } \\
\text { pharmaceuticals } \\
(\%)\end{array}$ \\
\hline Afghanistan & Low & 51 & 15 \\
\hline Bangladesh & Low & 18 & 38 \\
\hline Benin & Low & 32 & 15 \\
\hline Brazil & Upper-middle & 734 & 23 \\
\hline $\begin{array}{c}\text { Burkina } \\
\text { Faso }\end{array}$ & Low & 38 & 44 \\
\hline Burundi & Low & 84 & 30 \\
\hline Cambodia & Low & 42 & 37 \\
\hline Cameroon & Lower-middle & 61 & 44.5 \\
\hline Chile & Upper-middle & 787 & 14 \\
\hline $\begin{array}{l}\text { China } \\
\text { (Beijing) }\end{array}$ & Lower-middle & 177 & 45 \\
\hline Congo, DRC & Low & 70 & 20 \\
\hline Djibouti & Lower-middle & 16 & 23 \\
\hline Ecuador & Lower-middle & 255 & 26 \\
\hline Egypt & Low & 123 & 16 \\
\hline El Salvador & Lower-middle & 229 & 27 \\
\hline Ethiopia & Low & 15 & 39 \\
\hline Guinea, Rep. & Low & 19 & 21 \\
\hline Haiti & Low & 40 & 12.5 \\
\hline Honduras & Lower-middle & 117 & 42 \\
\hline India (Delhi) & Lower-middle & 45 & 15 \\
\hline Indonesia & Lower-middle & 55 & 27 \\
\hline Iran & Upper-middle & 269 & 13 \\
\hline Jordan & Upper-middle & 336 & 34.5 \\
\hline Kenya & Low & 33 & 23 \\
\hline Madagascar & Low & 18 & 25 \\
\hline Malawi & Low & 19 & 22 \\
\hline Malaysia & Upper-middle & 336 & 11 \\
\hline Mali & Low & 38 & 28 \\
\hline Mauritania & Low & 22 & 30 \\
\hline Mexico & Upper-middle & 515 & 25 \\
\hline Morocco & Lower-middle & 156 & 36 \\
\hline Myanmar & Low & 17 & 16 \\
\hline Mozambique & Low & 25 & 19 \\
\hline Nepal & Low & 25 & 30 \\
\hline Nigeria & Lower-middle & 69 & 23.7 \\
\hline Pakistan & Lower-middle & 23 & 27 \\
\hline Peru & Upper-middle & 201 & 24 \\
\hline Philippines & Lower-middle & 67 & 44 \\
\hline South Africa & Upper-middle & 485 & 12 \\
\hline Sri Lanka & Lower-middle & 84 & 25 \\
\hline Sudan & Lower-middle & 95 & 30 \\
\hline Syria & Lower-middle & 72 & 6 \\
\hline Tanzania & Low & 25 & 10 \\
\hline Thailand & Lower-middle & 168 & 29 \\
\hline
\end{tabular}

Table 1 continued

\begin{tabular}{llll}
\hline Country & $\begin{array}{l}\text { World Bank } \\
\text { income group } \\
(2010)\end{array}$ & $\begin{array}{l}\text { Health } \\
\text { expenditure per } \\
\text { capita }^{\mathrm{a}} \text { (\$US) }\end{array}$ & $\begin{array}{l}\text { Expenditure on } \\
\text { pharmaceuticals } \\
(\%)\end{array}$ \\
\hline Togo & Low & 29 & 37 \\
Tuvalu & Lower-middle & 290 & \\
Uganda & Low & 43 & 15 \\
Vanuatu & Lower-middle & 106 & 23 \\
Viet Nam & Lower-middle & 80 & 41 \\
Yemen & Lower-middle & 64 & 38 \\
Zambia & Low & 47 & 27 \\
Zimbabwe & Low & 78 & 21
\end{tabular}

${ }^{a}$ Figures for 2009 in \$US, except for Zimbabwe, where the figure is for $2008^{\mathrm{b}}$ (as \% of total health expenditure)

References: http://apps.who.int/medicinedocs/en/d/Js6160e/14.2.html [32]; http://data.worldbank.org/indicator/SH.XPD.PCAP [35]

countries, $46.1 \%(n=24)$ were low income, $38.5 \%$ $(n=20)$ were lower-middle income and $15.4 \%(n=8)$ were upper-middle income according to 2012 World Bank income group definition (see 'Methods').

\subsection{Availability}

\subsubsection{Beclometasone and Budesonide}

The availability in public hospitals of generic beclometasone $100 \mu \mathrm{g} /$ puff was $19 \%$ and of generic budesonide was $16 \%$. In the private sector, availability of beclometasone $100 \mu \mathrm{g} /$ puff inhaler (any brand) was $46 \%$ and of budesonide $200 \mu \mathrm{g} /$ puff inhaler (any brand) was $58 \%$ (Table 2). The branded reference product (Qvar ${ }^{\circledR}$ ) was only found in the private sector in El Salvador and Malaysia (Fig. 2).

Countries in which neither of the surveyed corticosteroid inhalers were available (any brand, any health facility) include Burundi, Cameroon, Congo, Djibouti, Ecuador, Haiti, Mauritania, Myanmar, Nigeria, Pakistan, Syria, Tanzania, Togo and Vietnam. Beclometasone $100 \mu \mathrm{g} / \mathrm{puff}$

Table 2 Overall availability (\%) of inhalers in 52 surveyed countries

\begin{tabular}{lllc}
\hline Inhaler & $\begin{array}{l}\text { Private } \\
\text { pharmacies }\end{array}$ & $\begin{array}{l}\text { National } \\
\text { procurement } \\
\text { centre }\end{array}$ & $\begin{array}{l}\text { Public } \\
\text { hospital }\end{array}$ \\
\hline Qvar $^{\circledR}$ inhaler & 4.2 & 0.0 & 0.0 \\
$\begin{array}{l}\text { Beclometasone } \\
\quad 400 \mu \mathrm{g} / \text { puff }\end{array}$ & 41.7 & 17.5 & 18.8 \\
$\begin{array}{l}\text { Pulmicort } \\
\text { B inhaler }\end{array}$ & 28.6 & 9.3 & 8.3 \\
$\begin{array}{l}\text { Budesonide 200 } \mu \mathrm{g} / \\
\text { puff }\end{array}$ & 30.0 & 11.9 & 16.3 \\
$\begin{array}{l}\text { Ventolin } \\
\text { Salbutamol } 200 \mu \mathrm{g} / \mathrm{puff}\end{array}$ & 82.4 & 54.8 & 28.9 \\
\hline
\end{tabular}


was only listed in 12 of the national medicines lists available, with a further 28 countries listing the $50 \mu \mathrm{g} / \mathrm{puff}$ strength (product not surveyed). Only 10 of the 52 surveyed countries listed budesonide $200 \mu \mathrm{g} / \mathrm{puff}$ (Fig. 2).

Absence of a medicine from a national EML did not necessarily equate to unavailability. In five countries where the $100 \mu \mathrm{g}$ beclometasone strength was not listed (Afghanistan, Mali, Nepal, Uganda and Vanuatu), the medicine was available at the public hospital surveyed. Where budesonide
$200 \mu \mathrm{g} /$ puff was not on the EML, the medicine was available at both the procurement centre and the surveyed public hospital in India, Peru and Tuvalu and in public hospitals only in a number of other countries (Fig. 2).

\subsubsection{Salbutamol}

Generic salbutamol inhalers were available in $55 \%$ of national procurement centres, $56 \%$ of public hospitals and

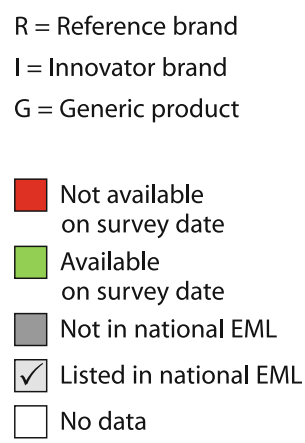

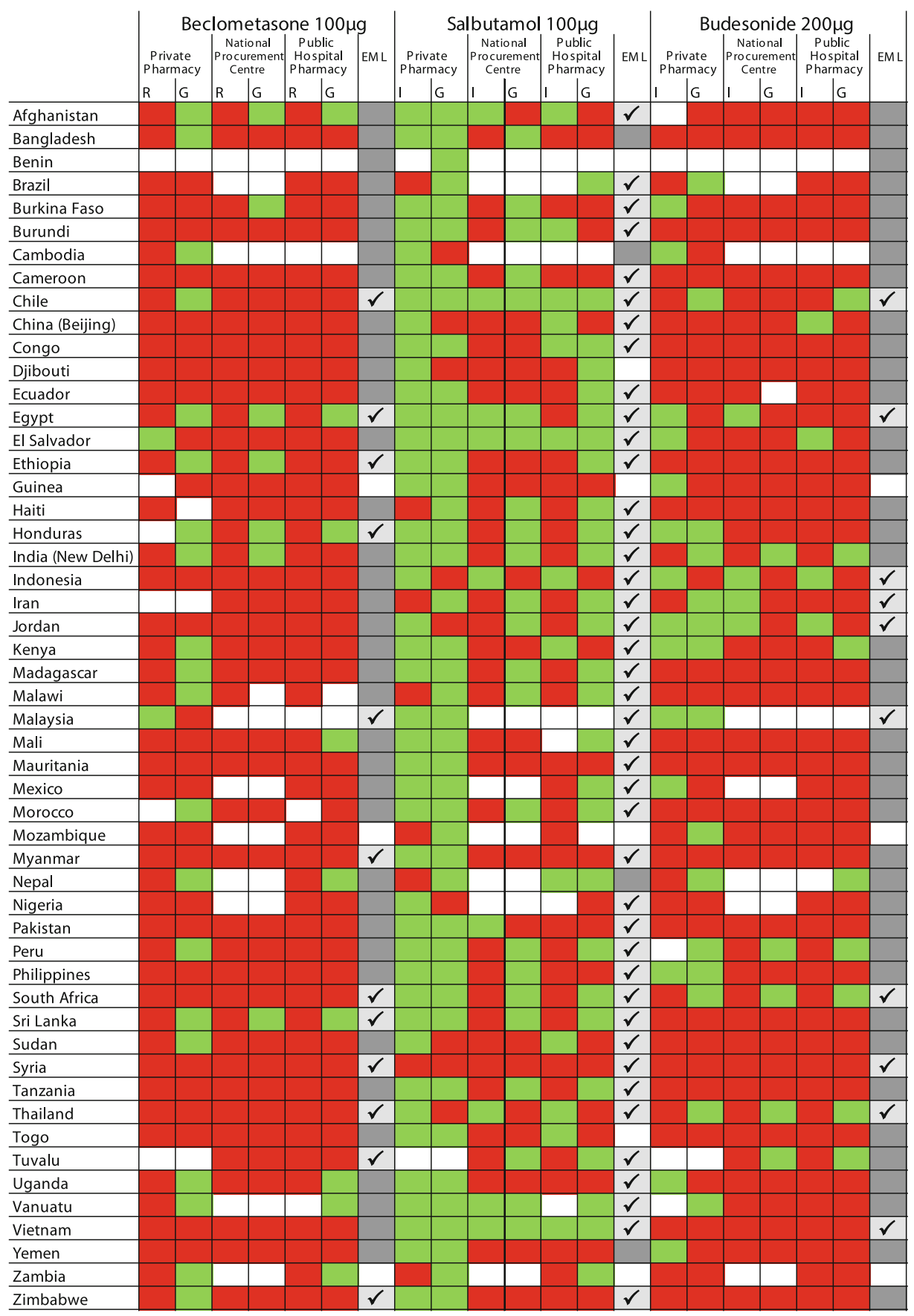

Fig. 2 Availability of surveyed inhalers by country, type of health facility and national Essential Medicines List (EML) 
$82 \%$ of private pharmacies (see Table 2). Only in Syria was salbutamol $100 \mu \mathrm{g} /$ puff inhaler (generic or IB) not available in any of the facilities surveyed on the survey date.

Inhaled salbutamol $100 \mu \mathrm{g} / \mathrm{puff}$ has been listed in the WHO EML for many years, and has made it onto the EMLs of almost all countries surveyed, with exceptions including Bangladesh, Cambodia, Nepal and Yemen (see Fig. 2).

\subsection{Price Ratio Comparisons}

\subsubsection{Beclometasone}

A total of 26 countries $(50.0 \%)$ provided at least one field of data for beclometasone across the three sectors under study (see Table 3). There were no pricing data from private pharmacies in Burkina Faso, while for Guinee Conakry, the private pharmacies price was very low (0.12), hence they were not included in Fig. 3, which shows the beclometasone pricing from private sector retail pharmacies.

Malaysia and El Salvador were the only two countries where IB beclometasone was available. In Malaysia, for the private retail pharmacy, the ratio to IRP was 1.87 , but the prices were considerably higher when compared with the ADF prices (11.77). In El Salvador, for the private retail pharmacy, the ratio to IRP was 3.72 and the ratio to ADF prices was 23.44.

When generic beclometasone was compared with the IRP, a price ratio of $<3$ was found in the private sector of all countries except for Chile, where the ratio was found to be 4.00. However, when compared with the ADF prices, a further 16 countries demonstrated comparatively higher private sector pricing. This represents $70.8 \%$ of the countries that provided data for at least one private sector site.

The procurement and/or public hospital pricing data from six countries (Afghanistan, Burkina Faso, Egypt, Ethiopia, India and Nepal) showed a price ratio of $<1$ when compared with IRP, suggesting efficient pricing of generic beclometasone. When the prices were compared with the $\mathrm{ADF}$, the ratios were higher, ranging from 1.52 for Afghanistan through to 5.41 for Nepal.

\subsubsection{Budesonide}

For IB budesonide in the private retail pharmacies, data were available from 12 countries in at least one site. When compared with IRPs, the IB was found to be $>3$ in the private retail pharmacies of Burkina Faso (9.75), Guinea Conakry (9.17), Mexico (3.22) and Yemen (3.99). When compared with the ADF prices, they were found to exceed the threshold of 3 in all 14 countries (see Fig. 4; Table 4).
IB budesonide was available in the national procurement centres of Egypt, Indonesia, Iran and Jordan and in the public hospitals in China, El Salvador, Indonesia and Jordan. When compared with ADF prices, the procurement prices were found to be high.

Pricing data for generic budesonide were reported from at least one private retail pharmacy in 15 countries. When compared with the IRP, price ratios were found to be $>3$ in four countries: Brazil (5.36), Mozambique (7.28), Philippines (3.08) and South Africa (4.85). When compared with ADF pricing, the price ratios were found to be extremely high in Brazil (21.77), Mozambique (29.56) and South Africa (19.70). The price ratios were noted to be high for private pharmacy data across most countries, except for India (2.60), Jordan (1.39), Kenya (2.92), Malaysia (1.74) and Nepal (2.32).

Generic budesonide was available in the national procurement centres of five countries: India, Peru, South Africa, Thailand and Tuvalu. When compared with the IRP, all of these countries report price ratios of $<1$, indicating efficient procurement. However, when compared with the ADF prices, they were all $>1$. For public hospitals, pricing data were available from Kenya, Nepal, Peru, South Africa, Thailand and Tuvalu. All countries reported a price ratio of $<1$ when compared with the IRP, except for Peru (1.14).

\subsubsection{Salbutamol}

The dataset for salbutamol was more complete than for either beclometasone or budesonide (see Fig. 5; Table 5). Data were available from all countries except for Syria.

In the national procurement centres, IBs were available in eight countries. There was a large range of prices for IB salbutamol, from Afghanistan with a ratio to IRP of 0.82 and a ratio to ADF prices of 1.30 through to Indonesia with 13.45 and 21.16, respectively. Afghanistan was the only country where the price ratio to IRP was found to be $<1$. When these prices were compared with ADF prices, the price ratios were high (see Fig. 5; Table 5). Public hospital data for IB salbutamol was obtained from 13 countries, and the price ratios to IRP ranged from close to one for Afghanistan (1.27) to nearly eight for Indonesia when compared with the IRP (7.57).

In private sector pharmacies, IB salbutamol pricing data were available from 42 countries. In 13 countries, when compared with IRPs, the price ratios were found to be $<3$. In five countries, it was found to be $<2$ : Afghanistan (0.76), Egypt (1.29), India (1.27), Kenya (1.41) and Pakistan (1.38). Even when these prices were compared with ADF, they were quite low. Those countries that have particularly high pricing ratios for the IB salbutamol in the private sector when compared with the IRPs include Chile (11.12), Indonesia (7.38), Mexico (16.85) and Thailand (8.41). 


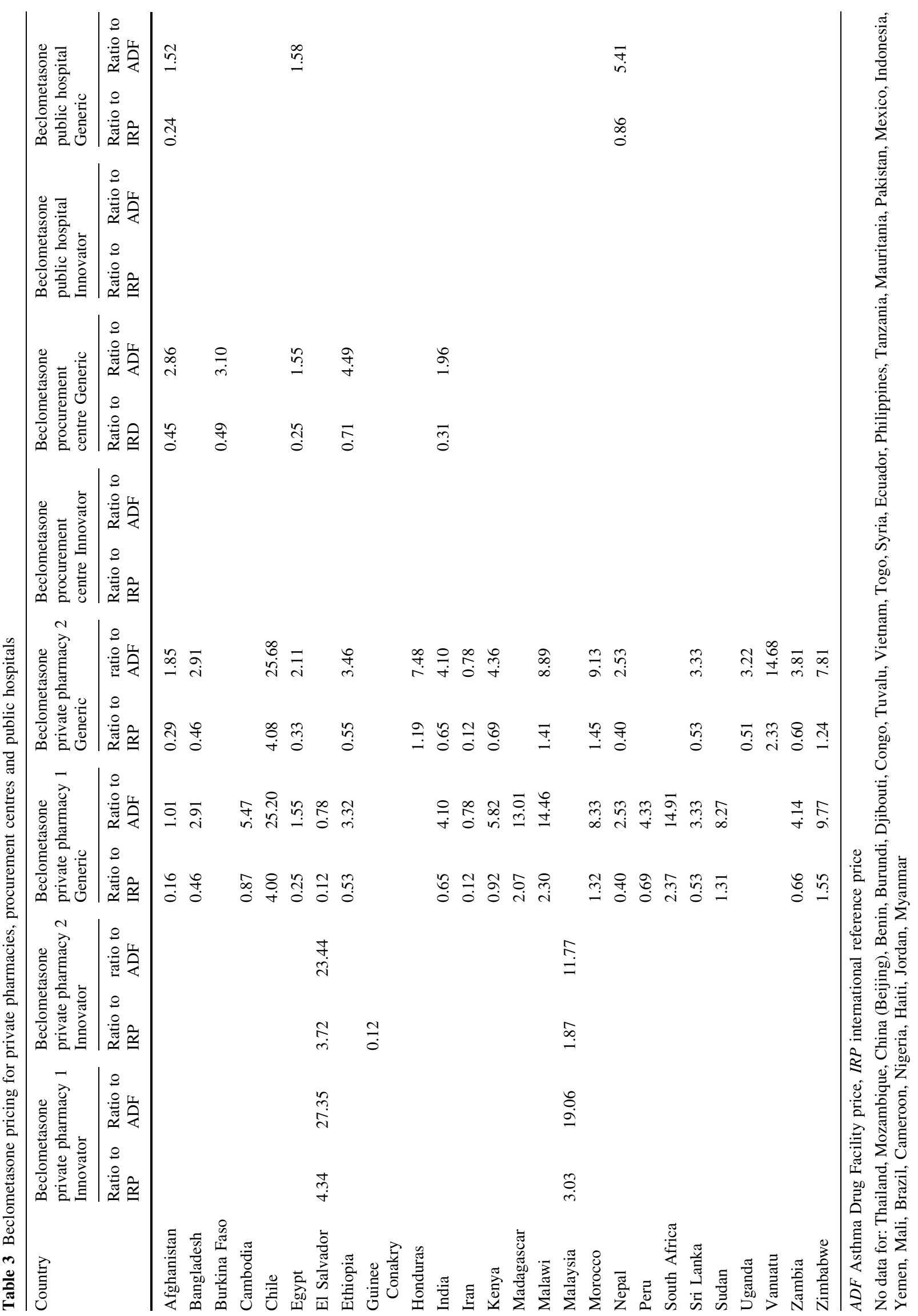




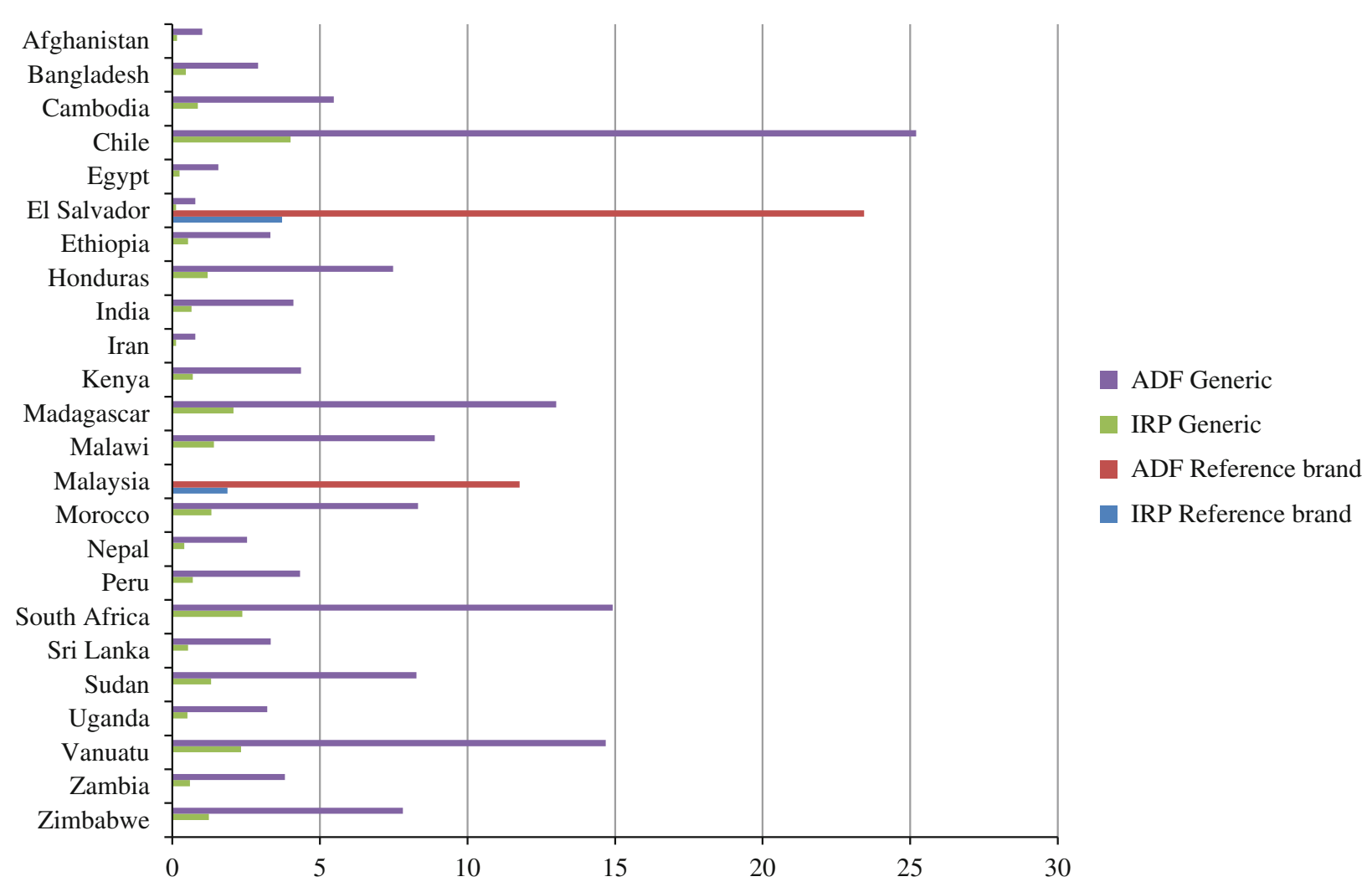

Fig. 3 Price ratio comparisons for beclometasone from private pharmacies. ADF Asthma Drug Facility price, IRP international reference price

The national procurement centre prices for generic salbutamol were available from 23 countries. There was a wide variation, ranging from lower prices for Jordan (IRP 0.53, ADF 0.83) through to higher prices for El Salvador (IRP 2.94, ADF 4.63). Of the 23 countries, 12 of them report a ratio $<1$ when compared with IRP, suggesting procurement efficiency. These countries were Bangladesh, Cameroon, Egypt, Honduras, India, Jordan, Madagascar, Morocco, Mozambique, Peru, Tanzania and Vanuatu. When the ratio to the ADF price was calculated, only Jordan (0.83), Mozambique (0.94) and Peru (0.99) demonstrated lower prices. No generic salbutamol was available at the national procurement centre in Indonesia. In the public hospital setting, generic salbutamol was available in 16 countries, and when the prices were compared with the IRP, only five countries, including Egypt, Ethiopia, Jordan, Mozambique and Peru demonstrated a ratio $<1$.

Wide variations were observed in private sector retail pharmacies when the generic salbutamol prices were compared with the IRP. When compared with the IRP in Afghanistan it was 0.63 , whereas it was 1.0 when compared with the ADF price. In Brazil, the figures were 16.80 and 26.44 , respectively. There were no data available from Cambodia, China, Djibouti, Indonesia, Jordan, Nigeria, Sudan, Thailand and Tuvalu.

\subsubsection{Difference in Price between Generic and Innovator Brands}

In the majority of cases, the price for IBs was higher than the lowest price for the generic. However, in India and Kenya, the price of IB salbutamol in private retail pharmacies was less than the generic. This was also the case for public hospital pricing for salbutamol in Nepal. In the Philippines, the price of generic budesonide was more than the IB from the same private sector pharmacy.

\subsection{Affordability of Medicines Purchased from Private Pharmacies}

The affordability of inhalers (when purchased from the private sector) was computed using the daily wage of the lowest-paid unskilled government worker and was based on the lowest-priced inhaler available (irrespective of brand). In some countries, surveyed medicines are provided free in the public sector, and social insurance may exist in the private sector. However, the data illustrate what 


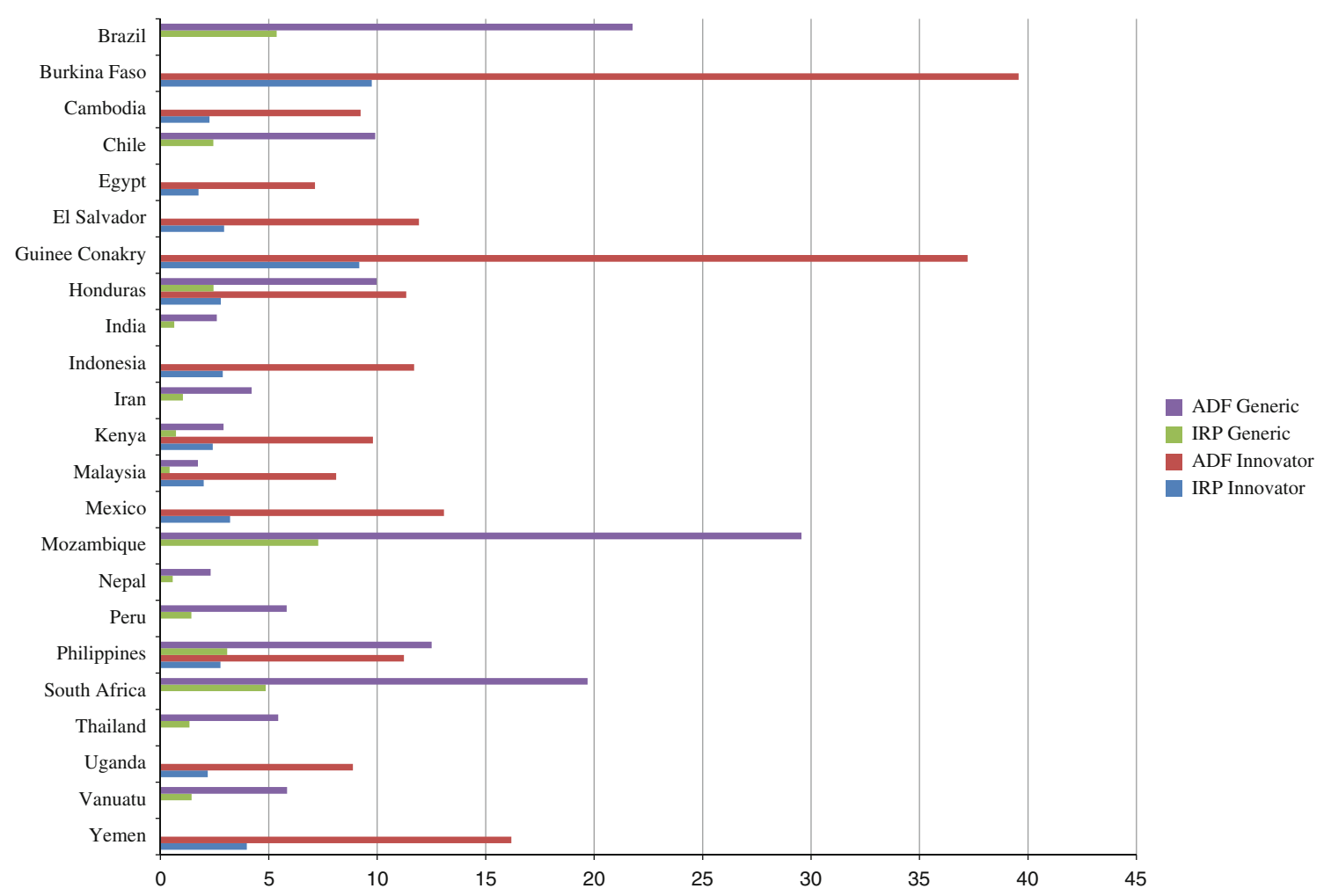

Fig. 4 Price ratio comparisons for budesonide sourced from the private sector. $A D F$ Asthma Drug Facility price, $I R P$ international reference price

patients would have to pay out-of-pocket in the private sector if they have no alternative.

Affordability data for beclometasone were made available by 23 countries (see Fig. 6).

Affordability of a single beclometasone $100 \mu \mathrm{g}$ inhaler ranged from around half a day's wages in Afghanistan to almost 14 days in Madagascar. The people from El Salvador, Ethiopia, Madagascar and Malawi had to work more than 5 days to pay for a single beclometasone inhaler in a private retail pharmacy.

Affordability data for budesonide were made available by representatives from 24 countries and there is much wider variation (see Fig. 7).

In Jordan, half a day's wages will purchase one budesonide inhaler, whereas 107 days' wages are required in the Republic of Guinea to purchase a single IB budesonide inhaler. In just over $54 \%$ of countries that provided data ( $n=13$ ), one budesonide inhaler costs 5 days' wages or less and, in $33 \%$ of countries $(n=8)$, at least 10 days of work. The outliers are Burkina Faso, Republic of Guinea and Mozambique, where the cost of a single budesonide $200 \mu \mathrm{g}$ inhaler equates to 48, 107 and 51 days' wages, respectively.
For both generic and brand salbutamol, the affordability was calculated for 42 countries (Fig. 8).

In over $40 \%$ of countries $(n=16)$, it costs less than 1 day of work to purchase generic salbutamol from a private sector pharmacy. In Burundi, Ethiopia, Indonesia, Madagascar, Mexico and Republic of Guinea, purchase of the IB salbutamol required more than 4.5 days' wages. In Benin, El Salvador, Republic of Guinea, Madagascar, and Mozambique, the cost of a single generic $100 \mu \mathrm{g}$ salbutamol inhaler is greater than 3 days of wages.

\section{Discussion}

This study set out to compare the availability, pricing and affordability of three essential asthma medicines in a selection of low- and middle-income countries. The majority of respondents $(84.6 \%)$ were from low or lowermiddle income countries; the rest were from upper-middle income countries. As far as the authors are aware, this is the largest survey of its kind exploring medicine pricing and affordability for corticosteroids and a bronchodilator in low- and middle-income countries. 


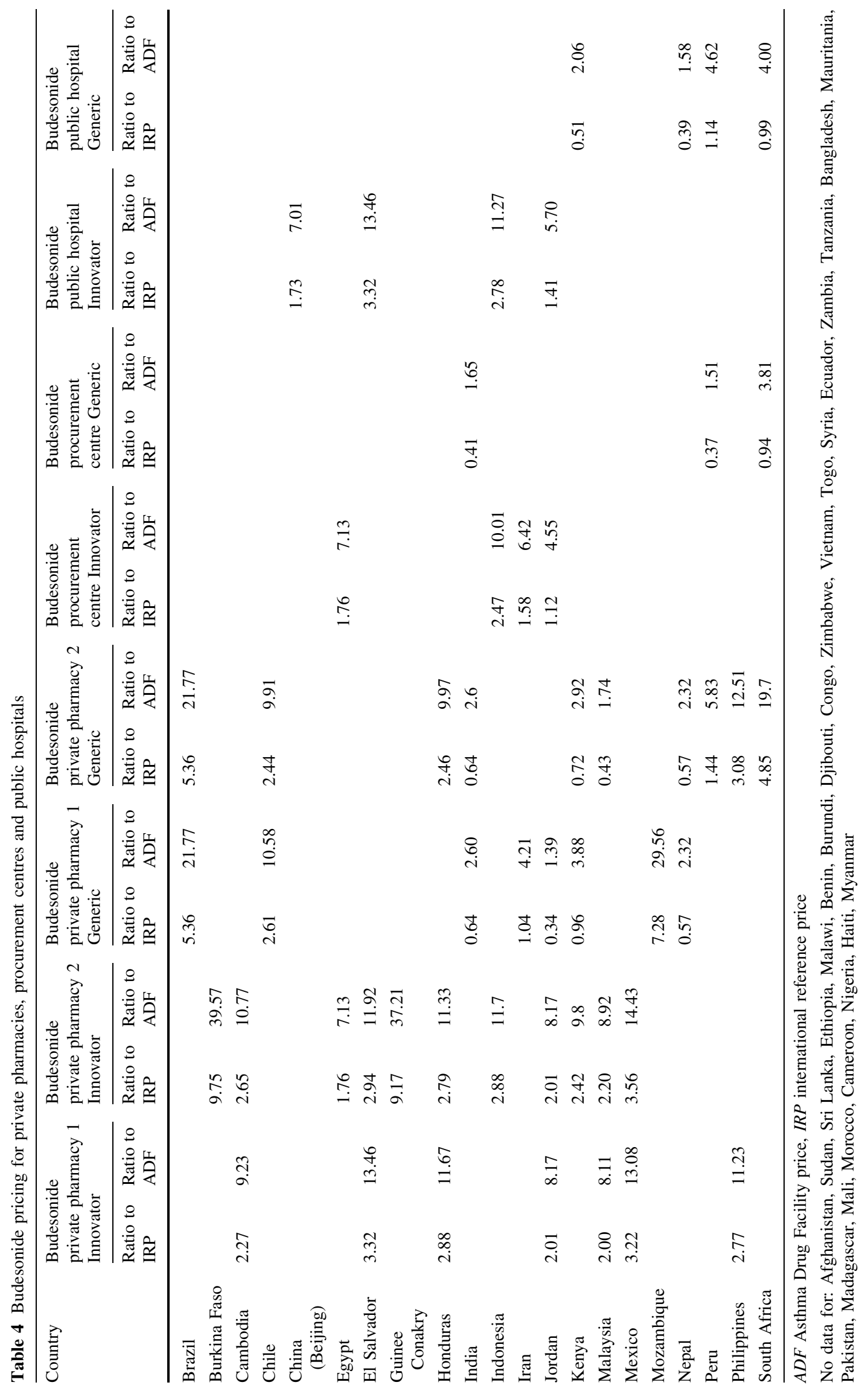




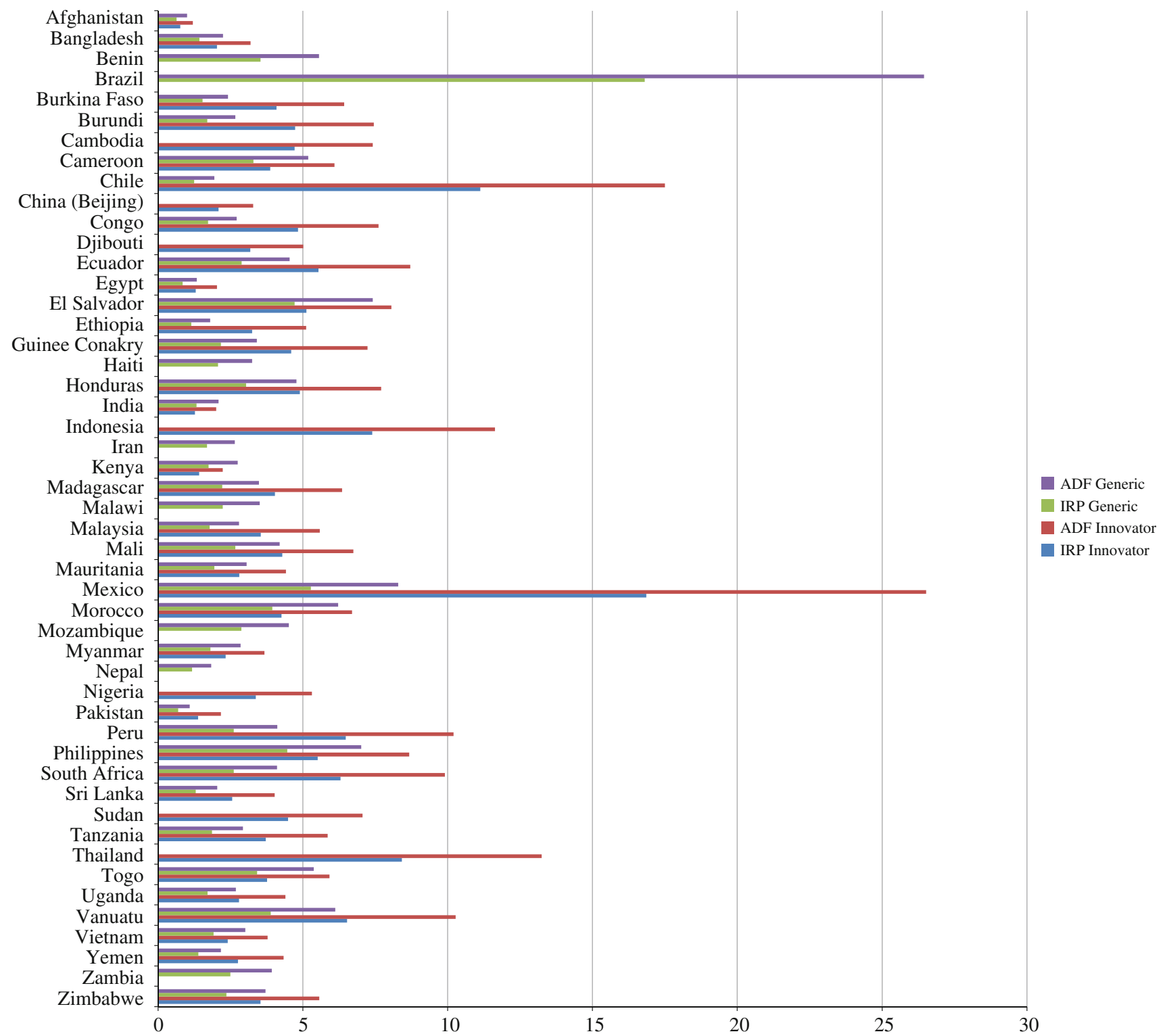

Fig. 5 Price ratio comparisons for salbutamol from private pharmacies. ADF Asthma Drug Facility price, IRP international reference price

\subsection{Summary of Findings and Relevance to Literature}

When calculating price ratios with MSH IRPs, the data suggest that many countries have efficient procurement systems. However, when ratios are calculated with ADF pricing, there is a demonstrable reduction in procurement efficiency for the three asthma medicines within and across private retail pharmacies, national procurement centres and public hospital sites. This has not previously been reported in the literature and there are significant implications for health policy makers responsible for medicines procurement, which is considered later in this discussion.

Neither beclometasone nor budesonide are available to the extent that salbutamol is [21]. This may be due to national standard treatment guidelines not being adhered to or not being in line with WHO recommendations, as well as patient-related factors such as lack of education about using both medicines and reluctance to use corticosteroids. In addition to providing information that has been lacking about the availability and pricing of corticosteroids, this work also provides more up-to-date information than previously reported for salbutamol procurement in the developing world [22].

Some countries reduce the price of asthma medicines to patients as part of health service delivery, while other countries are applying high margins to the patient price. This suggests huge variation between countries in terms of commitment to accessible healthcare. The difference in 


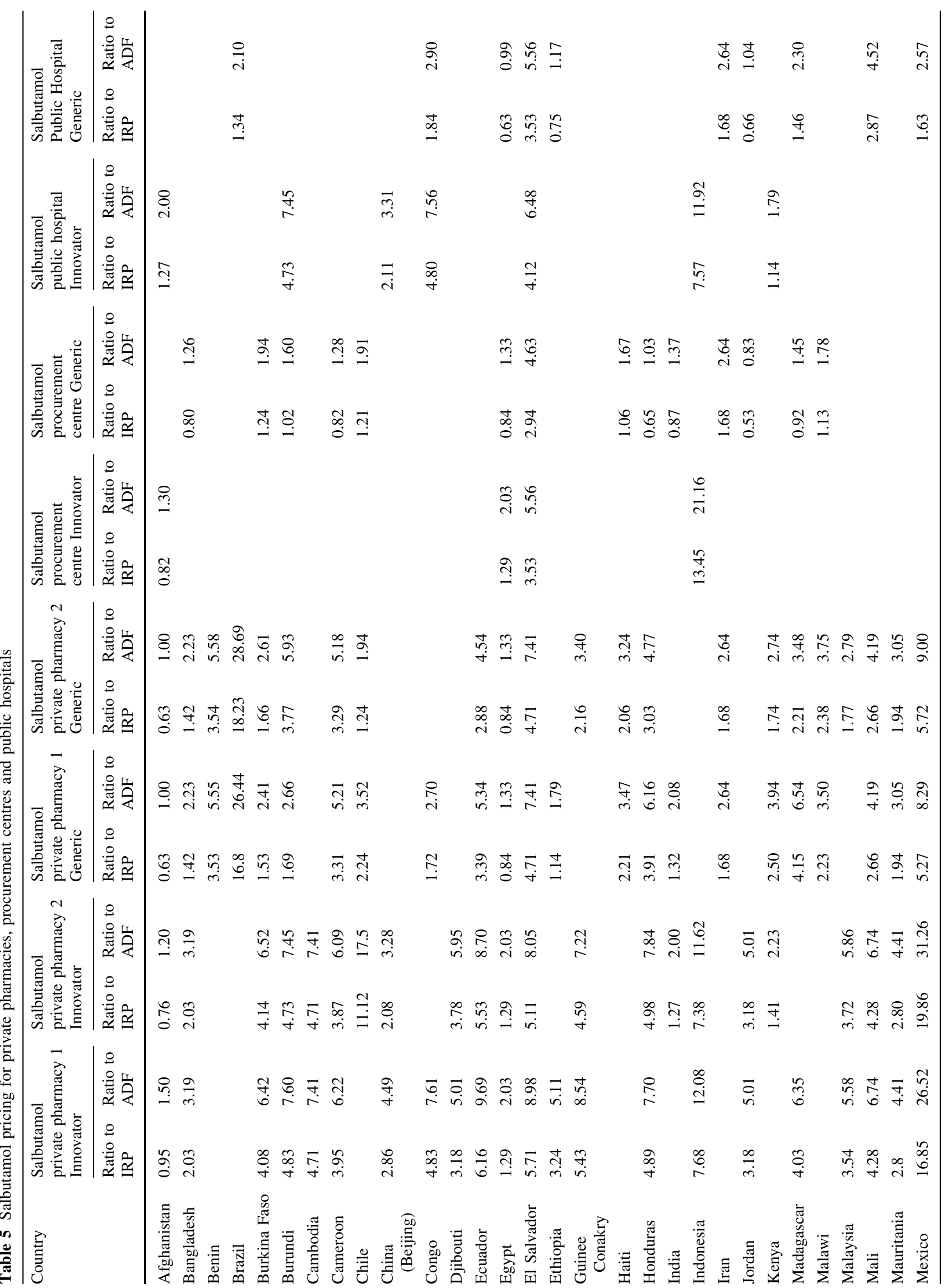




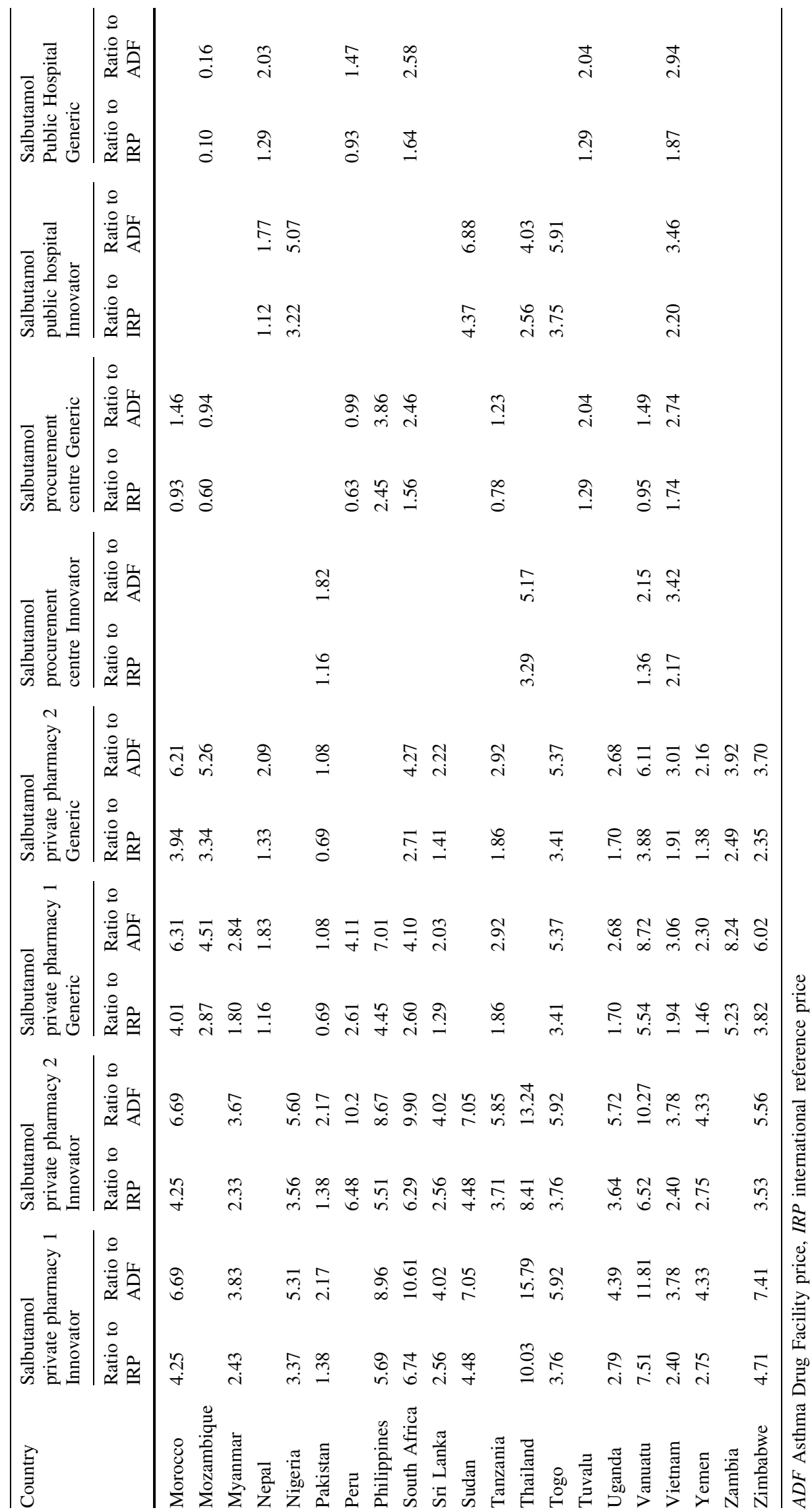


Fig. 6 Affordability (number of days wages per inhaler) of beclometasone $100 \mu \mathrm{g}$ inhaler in private pharmacies

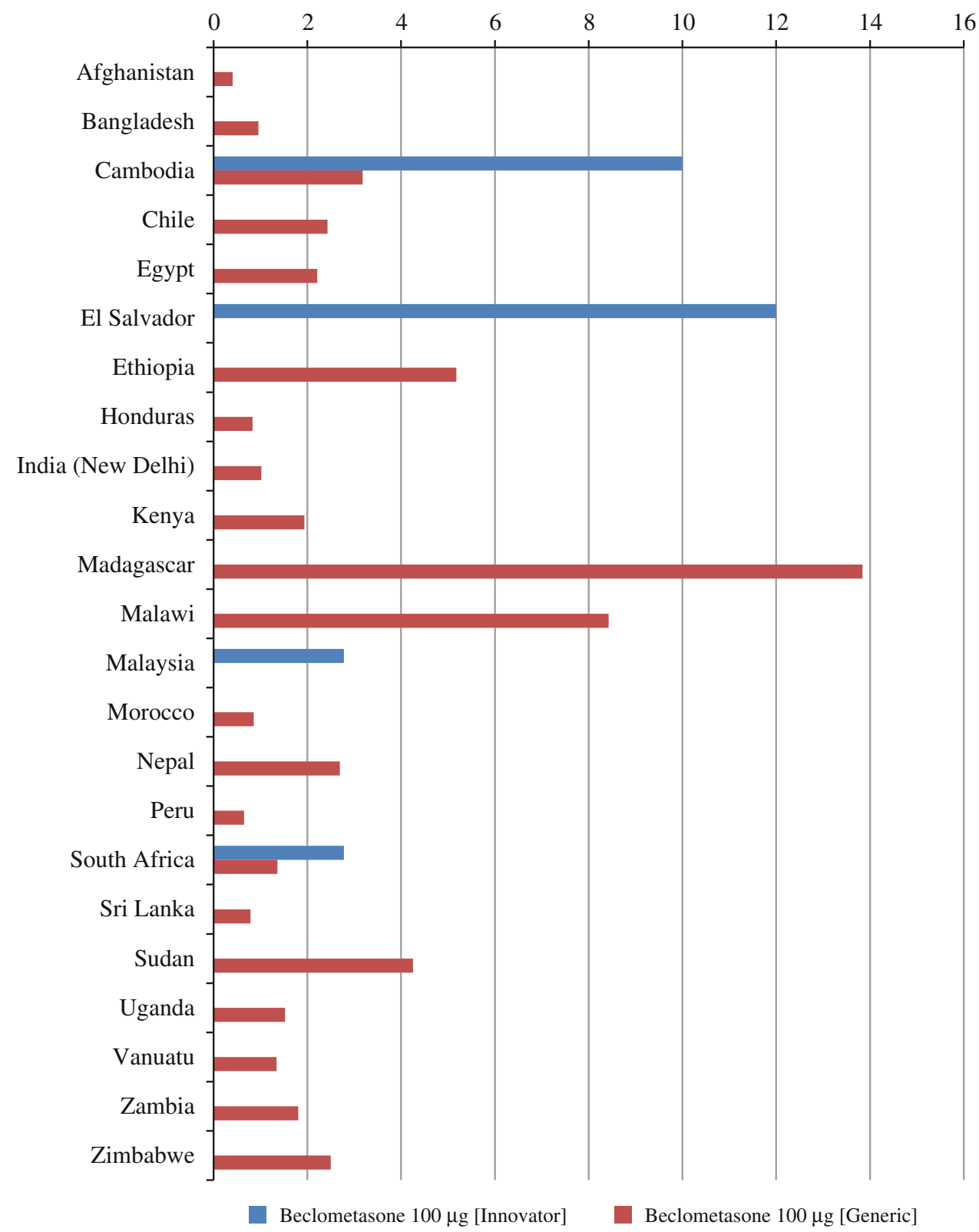

price for the patient within public hospitals compared with catalogue prices from national procurement centres provides a proxy for determining levels of subsidy or the level of margin applied. It could also be due public hospitals not using the national procurement centres to buy asthma medicines. The percentage differences vary from an $83 \%$ subsidy for generic salbutamol in Mozambique to a $206 \%$ margin for generic budesonide in Peru. This suggests that, in some countries, individuals face inflated 'out-of-pocket' costs in order to access essential asthma medicines.

The affordability of a full range of asthma medicines in low- and middle-income countries has not been well explored [2, 29, 32]. Over 36 pricing studies in developing countries have been cited in the literature, the majority of which only include salbutamol data. The work of Kotwani et al. in India contributes significantly to these primary studies [22, 29]. This paper updates the current status of salbutamol pricing in a larger cohort of countries, as well as including beclometasone and budesonide; the latter of which has not been reported in any studies and is not included in the WHO/HAI survey templates.

In this study, affordability was based on inhaler prices and a generalised daily minimum wage. It should be noted that, in some countries, medicines may be provided for free. This study found marked variation in the affordability of asthma medicines from private retail pharmacies in lowand middle-income countries. Previously, pricing and affordability data have only been available for salbutamol. 
Fig. 7 Affordability (number of days wages per inhaler) of budesonide $200 \mu \mathrm{g}$ inhaler in private pharmacies

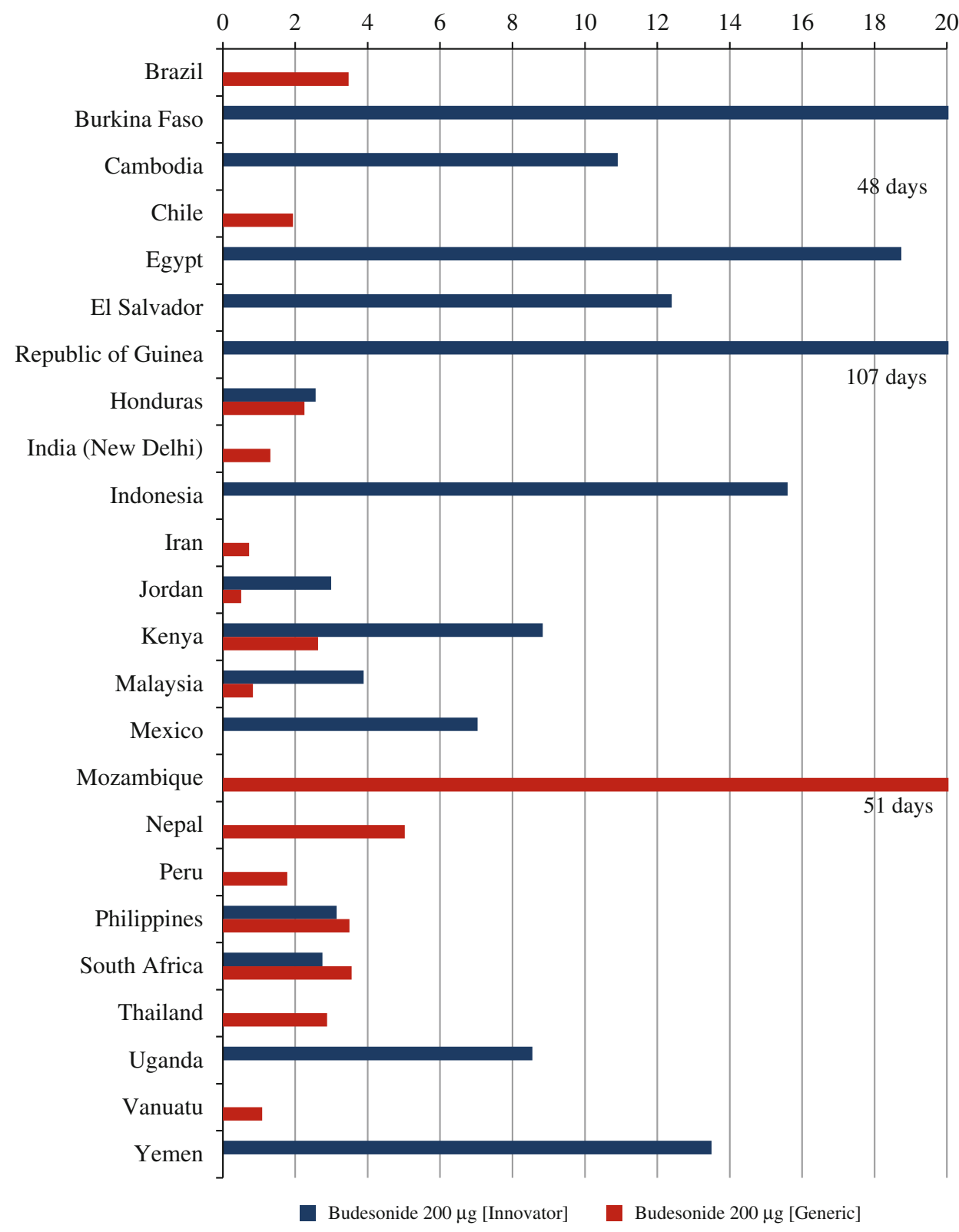

Cameron et al. [2] report that the purchase of one generic salbutamol inhaler in a private pharmacy sector would equate to a maximum of 5 days' wages for the lowest-paid government worker in a selection of low- and middleincome countries. This study supports that finding, since we found that, in all countries, 4 days or less wages are required to pay for one generic salbutamol inhaler (i.e. 32 days' wages/year for the estimated eight inhalers required).

Literature to compare with the findings of this work are scarce when it comes to the affordability of beclometasone and budesonide. The affordability of generic beclometasone appears to closely match that of generic salbutamol, with less than 5 days' work needed to purchase a single inhaler, except in Ethiopia, Madagascar and Malawi. The affordability of budesonide demonstrates wider extremes. For generic budesonide, it ranges from less than one day's wage for a single inhaler in Iran, Jordan and Malaysia to more than 50 days' wages in Mozambique. This variation requires further investigation.

From a methodological viewpoint, this study makes a contribution through providing more robust data sources for budesonide and beclometasone than the MSH 2010 list [26]. This study provides at least eight data points for both corticosteroids, whereas the MSH IRPs are based on one and two data points for these medicines, respectively.

Importantly, this study alerts researchers to the risks involved with using IRPs to measure whether the prices are 
Fig. 8 Affordability (number of days wages per inhaler) of salbutamol $100 \mu \mathrm{g}$ inhaler in private pharmacies

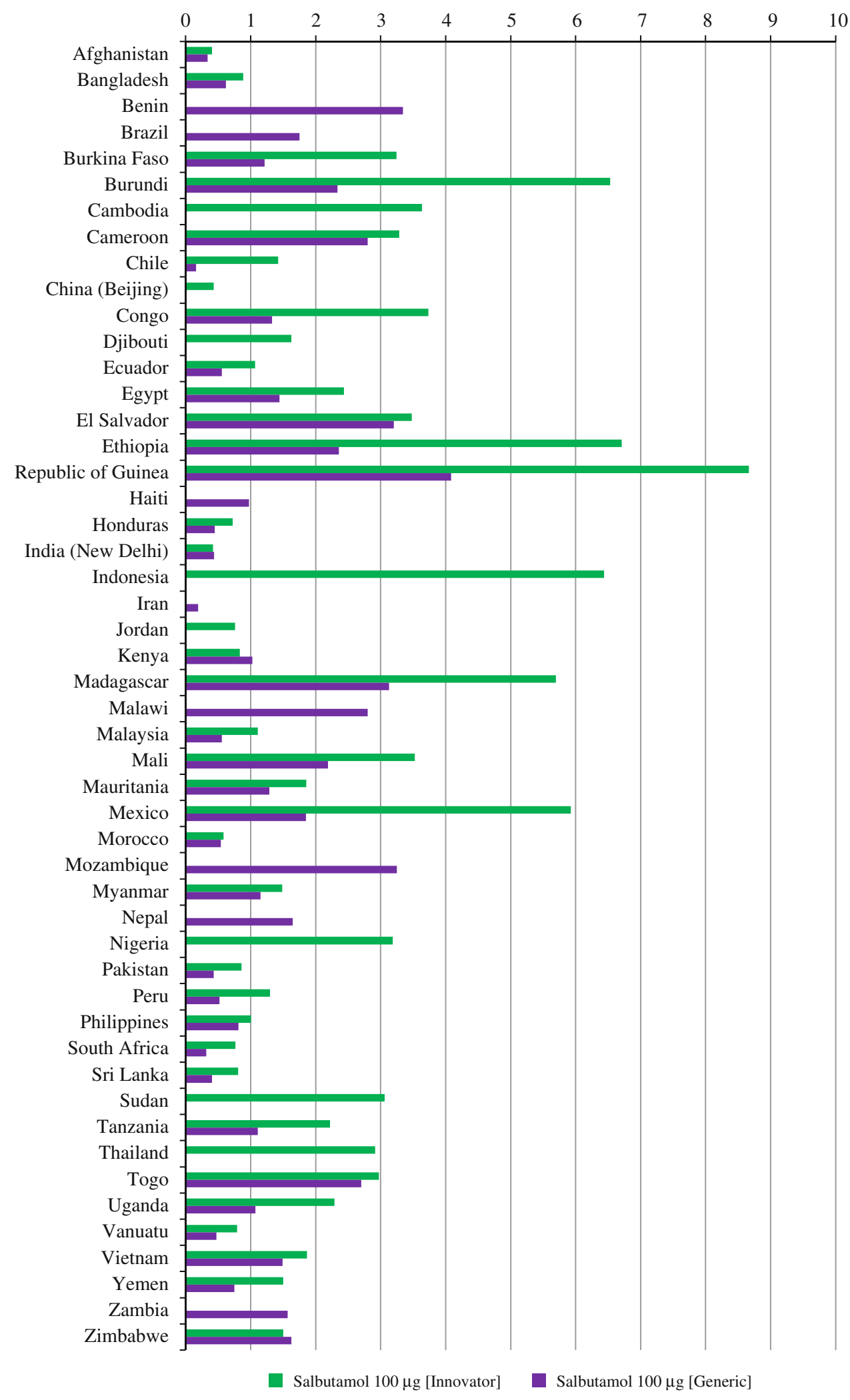

high or low in a given context. Although it is crucial to have standardised methodologies for measuring and monitoring medicine prices, IRPs can be misleading, as they are not all based on robust selection of international not-for-profit prices. Policy makers and lay readers may presume that IRPs are the price a medicine 'should' be, unless told otherwise. In the case of this study, beclometasone and budesonide IRPs were based on two outlier-type prices and 
only one price, respectively, thus making prices appear acceptable when they most definitely were not when compared with ADF prices, even considering that ADF prices would be among the lowest in the world. The limitations of IRPs should be made clear in all publications using them. For the greatest transparency, articles using IRP methodology would include a table showing the data used by MSH to construct the relevant IRPs, thus allowing readers to contextualise the prices and the conclusions made about appropriateness of prices and efficiency of procurement.

\subsection{Implications of the Findings for Policy, Practice and Future Research}

Availability was particularly low for the inhaled corticosteroids. This is concerning, given their importance in the management of asthma. It appears that many patients in these countries only access a bronchodilator, which, for patients with moderate to severe asthma, would mean that their asthma is being very poorly controlled [31].

Moreover, many national EMLs did not include the two WHO-recommended inhaled corticosteroids. This may reflect a situation where the available national EML was not the latest version, or may be indicative of standard treatment guidelines, training programmes and/or prescription behaviour not being consistent with the national EML. It may be that many EMLs still list only the strengths of beclometasone that were used before inhalers propelled by chlorofluorocarbons (CFC) were phased out and the strength using hydrofluoroalkanes (HFA) became $100 \mu \mathrm{g}$ [33]. This may be leading to confusion for procurement officials, pharmacists, other healthcare workers and patients. Although it is possible that other inhaled corticosteroids were available in these countries, or that strengths other than those surveyed were available for beclometasone or budesonide, these are matters for health services to investigate urgently.

Corticosteroid prices remain very high in many countries. This is reflected in the IRPs as well as in the country data. The IRP for beclometasone is six times higher than the ADF's current price; IRP budesonide is four times higher. This variation should alert policy makers and health services to the disparities that exist within and between the countries surveyed as part of this work. Most health systems are spending much more than they need, and there are many examples of acute lack of affordability for patients. Public sector national procurement centre efficiency could thus be improved in many countries through policy changes such as pooled purchasing, competitive tendering or procurement through mechanisms such as the ADF.

Procurement of generic medicines is generally expected to result in cost savings and improved affordability. However, some unusual, and as yet unexplained, anomalies emerged in this study. For example, in India and Kenya, the unit cost of generic salbutamol is more expensive than the IB. The same applies to public hospital pricing in Nepal. In Philippines, generic budesonide was more expensive than the IB. These anomalies require further investigation.

\subsection{Limitations}

This study has a number of limitations. First, data were collected for single strengths of the three asthma essential medicines only. Other strengths, as well as other types of asthma medicines, may have been available, but the study did not set out to report on these. Thus, there may be more asthma medicines being sold-not that this would necessarily lead to good asthma management.

Second, it was not within the scope of the study to investigate product quality. Instead, we have to consider that it is the responsibility of the National Medicine Regulatory Authority (NMRA) to assess in a consistent way the quality, safety and efficacy of the medicines available in the country and to register them, whether they are IBs or generic products. Thus, we work with the assumption that our price comparisons are made on quality-assured products, although in practice national-level capacity for assuring quality may vary.

Third, this is a point-in-time sampling study and data were only collected from two private retail pharmacy sites, a single public hospital and the national procurement centre. Although the private pharmacies and hospitals included were all located in the centre of a capital city or other main city, where one could reasonably expect that availability would at least not be challenged by geographical barriers, the results are less generalisable than if multiple sites were sampled within countries. Fourth, this was a cross-country pricing survey, and the way in which asthma medicines are used in the different countries and the context surrounding the different health systems was not part of this study's methodology.

Fifth, it is not possible to verify that pharmaceuticals made available to patients at public hospitals are the same units purchased from the national procurement centre. Finally, affordability has been calculated using methodology validated in previous WHO/HAI studies [2]. The limitations of using the daily wage of the lowest-paid unskilled government worker, including the knowledge that a significant proportion of the population will earn less than this amount, have been recognised [34].

\section{Conclusion}

This study set out to explore the availability, pricing and affordability in low- and middle-income countries of three 
essential medicines (beclometasone, budesonide and salbutamol) used for the management of asthma. These findings hold significant implications for policy makers, healthcare professionals, researchers and those representing patients and consumers. Of note, the availability of inhaled corticosteroids was particularly low, and many national EMLs appear not to have been updated to incorporate inhaled corticosteroids and/or HFA doses of the same. Considerable variation was found in the pricing structures across the countries, and most procurement systems appeared to be inefficient when ADF prices were used to calculate ratios. There was also significant variation in the affordability of these three medicines across countries; some providing subsidies, while others appeared to apply high prices for patients. Thus, availability of the WHO-recommended essential asthma medicines appears to remain problematic; many health systems and patients appear to be paying more than necessary for asthma medicines, and many prices are unaffordable for patients.

Acknowledgments The authors would like to acknowledge the support of data collectors in all countries that provided data. We also acknowledge the technical support provided by Mrs Esther Ho at the International Union Against Tuberculosis and Lung Disease Asia Pacific, Singapore. KB and CM were working on the ADF project at The Union during the study period. The study was conducted through a grant provided by the International Union Against Tuberculosis and Lung Disease to ZB. CL was employed as research assistant to conduct part of this work. ZB conceptualised the study together with $\mathrm{KB}, \mathrm{CL}$ and $\mathrm{CM}$. The data collection, entry and analysis was handled by $\mathrm{CL}, \mathrm{KB}$ and $\mathrm{ZB}$. ZB wrote the manuscript together with the help of $\mathrm{KB}, \mathrm{CL}$ and $\mathrm{CM}$. The final version is approved by all authors. $\mathrm{ZB}$ acts as an overall guarantor to this study.

\section{References}

1. World Health Organization. WHO Model List of Essential Medicines. Geneva: World Health Organization; 2011. http://www. who.int/medicines/publications/essentialmedicines/en/. Accessed 17 Sep 2013.

2. Cameron A, Ewen M, Ross-Degnan D, Ball D, Laing R. Medicine prices, availability, and affordability in 36 developing and middle-income countries: a secondary analysis. Lancet. 2009;373:240-9.

3. Quick J, Rankin J, Laing R, O'Connor R, Hogerzeil H, editors. Managing drug supply. 2nd ed. West Hartford: Kumarian Press; 1997.

4. Creese A, Gasman N, Mariko M. The World Medicines Situation. Geneva: World Health Organization; 2004. http://apps.who.int/ medicinedocs/en/d/Js6160e/. Accessed 15 Aug 2013.

5. Management Sciences for Health. International drug price indicator guide. Boston: Management Sciences for Health; 2005. http://erc.msh.org/mainpage.cfm?file=1.0.htm\&module=Dmp\&lan guage=English. Accessed $1 \mathrm{Feb} 2011$.

6. Organization for Economic Co-operation and Development (OECD). Drug spending in OECD countries up by nearly a third since 1998, according to new OECD data (2005). http://www. oecd.org/document/25/20,2340,en_2649_37407_34967193_349 67191_34967191_34967191_34937407,34967100.html. Acce ssed 13 Aug 2013.

7. Hogerzeil H. MDG target 8E gap analysis. Geneva: World Health Organization; 2008.

8. Millennium Development Group Gap Task Force. Delivering on the global partnership for achieving the millennium development goals: MDG Gap Task Force Report. New York: United Nations; 2008.

9. World Health Organization. The World Medicines Situation 2011. WHO/EMP/MIE/2011.2.1. Geneva: World Health Organization; 2011.

10. Mendis S, Fukino K, Cameron A, et al. The availability and affordability of selected essential medicines for chronic diseases in six low- and middle-income countries. Bull World Health Organ. 2007;85:279-88.

11. World Health Organization (WHO) and Health Action International (HAI). Medicine prices-a new approach to measurement, Geneva (2003). http://whqlibdoc.who.int/hq/2003/WHO_EDM_ PAR_2003.2002.pdf.

12. World Health Organization. Chronic respiratory diseases. Geneva: World Health Organization. http://www.who.int/gard/publicati ons/chronic_respiratory_diseases.pdf. Accessed 17 Sep 2013.

13. Asher MI, Montefort S, Björkstén B, et al. Worldwide time trends in the prevalence of symptoms of asthma, allergic rhinoconjunctivitis, and eczema in childhood: ISAAC phases one and three repeat multicountry crosssectional surveys. Lancet. 2006;368:733-43.

14. Lai CKW, Beasley R, Crane J, et al. Global variation in the prevalence and severity of asthma symptoms: phase three of the International Study of Asthma and Allergies in Childhood (ISAAC). Thorax. 2009;64:476-83.

15. Chinn S, Jarvis D, Burney $P$, et al. Increase in diagnosed asthma but not in symptoms in the European Community Respiratory Health Survey. Thorax. 2004;59:646-51.

16. Rabe KF, Adachi M, Lai CK, et al. Worldwide severity and control of asthma in children and adults: the global asthma insights and reality surveys. J Allergy Clin Immunol. 2004; 114:40-7.

17. Lalloo UG, McIvor RA. Management of chronic asthma in adults in diverse regions of the world. Int $\mathbf{J}$ Tuberc Lung Dis. 2006; 10:474-83.

18. Bahadori K, Doyle-Waters MM, Marra C, Lynd L, Alasaly K, et al. Economic burden of asthma: a systematic review. BMC Pulm Med. 2009;9:24.

19. Jonsson B. Measuring the economic burden in asthma. In: Weiss K, Buist AS, Sulivan SD, editors. Asthma's Impact on Society: the social and economic burden. New York: Marcel Dekker; 1999. pp. 251-267.

20. Lai CKW, Kim Y-Y, Kuo S-H, et al. Cost of asthma in the Asia Pacific region. Eur Resp Rev. 2006;15:10-6.

21. Ait-Khaled N, Anderson H, Asher M, Babar Z, Bissell K, et al. (2011) Global Asthma Report. Paris: International Union against Tuberculosis and Lung Disease and The International Study of Asthma and Allergies in Childhood. http://www.globalasthmare port.org/. Accessed 15 Aug 2013.

22. Kotwani A. Availability, price and affordability of asthma medicines in five Indian states. Int J Tuberc Lung Dis. 2009; 13:574-9.

23. Mace C, Bissell K, Billo N. Access to essential asthma medicines: the response of the Asthma Drug Facility. World Health Organization Essential Medicines Monitor: 2011;5.

24. The World Bank. GNI per capita, Atlas method (current US\$) [online]. http://data.worldbank.org/indicator/NY.GNP.PCAP.CD. Accessed 17 Sep 2013.

25. Liamputtong PED. Qualitative research methods. Melbourne: Oxford University Press; 2005. 
26. McFadyen JE. International drug price indicator guide. Boston: Management Sciences for Health; 2010. pp E3 to P2-18.

27. WHO/HAI. Measuring medicine prices, availability, affordability and price components. Geneva: World Health Organization/ Health Action International; 2008.

28. Babar ZUD, Ibrahim MIM, Singh H, Bukahri NI, Creese A. Evaluating drug prices, availability, affordability, and price components: implications for access to drugs in Malaysia. PLoS Med. 2007;4:e82.

29. Gelders S, Ewen M, Noguchi N, Laing R. Price, availability and affordability: an international comparison of chronic disease medicines. World Health Organization and Health Action International; 2006. http://www.who.int/medicines/publications/Price AvailAfordability.pdf. Accessed 10 Aug 2013.

30. Aït-Khaled N, Enarson DA, Chiang C-Y, Marks G, Bissell K. Management of asthma: a guide to the essentials of good clinical practice. 3rd ed. Paris: International Union Against Tuberculosis and Lung Disease; 2008. http://www.theunion.org/index.php/en/ resources/technical-publications/. Accessed 17 Sep 2013.

31. Global Initiative for Asthma. Pocket guide for asthma prevention and management. 2011. http://www.ginasthma.org/local/upload s/files/GINA_Pocket_April20_1.pdf. Accessed 17 Sep 2013.

32. World Health Organization. The World Medicines Situation. Geneva: World Health Organisation; 2004.

33. Keith J, McDonald GPM. Transition to CFC-free metered dose inhalers-into the new millennium. Int J Pharm. 2000;201: 89-107.

34. Niëns LM, Cameron A, Van de Poel E, Ewen M, Brouwer WBF, et al. Quantifying the impoverishing effects of purchasing medicines: a cross-country comparison of the affordability of medicines in the developing world. PLoS Med. 2010;7:1-8.

35. The World Bank. Health expenditures per capita. http://data. worldbank.org/indicator/SH.XPD.PCAP. Accessed 17 Sep 2013. 